\title{
It Is Time to Consider Glucagon-Like Peptide-1 Receptor Agonists for the Treatment of Type 2 Diabetes in Youth
}

\author{
Megan M. Oberle ${ }^{1,2 *}$ and Aaron S. Kelly $y^{1,2}$ \\ ${ }^{1}$ Department of Pediatrics, University of Minnesota, Minneapolis, MN, United States, ${ }^{2}$ Center for Pediatric Obesity Medicine, \\ University of Minnesota Medical School, Minneapolis, MN, United States
}

Keywords: GLP-1 receptor agonists, pedatrics, type 2 diabetes, obesity, weight management, adolescents

\section{OPEN ACCESS}

Edited by:

Tuomas Kilpeläinen,

University of Copenhagen, Denmark

Reviewed by:

Kayte Jenkin,

Western Sydney University, Australia

Themistoklis Tzotzas,

St. Luke's Hospital, Greece

*Correspondence:

Megan M. Oberle

moberle@umn.edu

Specialty section:

This article was submitted to

Obesity,

a section of the journal

Frontiers in Endocrinology

Received: 19 August 2019 Accepted: 14 October 2019

Published: 29 October 2019

Citation:

Oberle MM and Kelly AS (2019) It is

Time to Consider Glucagon-Like

Peptide-1 Receptor Agonists for the

Treatment of Type 2 Diabetes in Youth.

Front. Endocrinol. 10:738.

doi: 10.3389/fendo.2019.00738
Prior to the SEARCH for Diabetes in Youth, a large multicenter study that described the prevalence of diabetes in the pediatric population, type 2 diabetes (T2DM) was mainly thought of as a disease of adulthood. However, SEARCH highlighted the startling rise in the prevalence of T2DM in children, adolescents, and young adults in the United States, citing a nearly 30\% increase between 2001 and 2009 (1). Although much was known about the etiology of T2DM and time-course of treatment failure in adults, relatively little was known about the increasing pediatric population with T2DM until the Treatment Options for T2DM for Adolescents and Youth (TODAY) Study in 2012. The TODAY study highlighted that youth with T2DM have earlier and more rapid deterioration of $\beta$-cell function than adults despite treatment with two anti-diabetic agents (metformin and rosiglitazone) $(2,3)$. The median time to treatment failure (defined as defined as HgbA1c $\geq 8 \%$ over 6 months, inability to wean insulin within three months of its initiation, or need to begin insulin therapy) was approximately 1 year for metformin monotherapy, metformin plus rosiglitazone, or metformin plus intensive lifestyle modification (2). Additionally, youth with T2DM were more likely to have kidney disease, dyslipidemia, retinopathy, and/or hypertension at baseline and experience earlier incidence of these co-morbidities than adults (2). Despite the poor outcomes with standard treatments and the evidence suggesting that the pathophysiology of T2DM in youth is particularly aggressive, metformin and insulin were the only FDA-approved treatments for youth with T2DM in the U.S. until recently (4-7). Unfortunately, neither metformin nor insulin target the underlying $\beta$-cell dysfunction, meaningfully reduce excess adiposity, or reasonably delay the need to initiate insulin to maintain glycemic control (8).

In the TODAY study and in clinical practice, failure of metformin and lifestyle modification often required the initiation of insulin therapy earlier than desired as a means of rapidly improving glycemic control to delay the long-term sequelae of hyperglycemia (nephropathy, neuropathy) $(3,5)$. The International Society for Pediatric and Adolescent Diabetes (ISPAD) Clinical Practice Guidelines recommend starting basal insulin if a patient fails to reach $\mathrm{HbAlc}<6.5 \%$ after $3-4$ months of metformin monotherapy and adding meal time or correction rapid-acting insulin if the goal HbAlc is not achieved (5). However, insulin-associated weight gain can be a barrier to adherence and negatively influence motivation to lose weight in youth with T2DM (9). The recommendation to start insulin therapy following metformin failure in youth is in contrast to the guidelines for adults with T2DM, which recommend avoidance of insulin therapy because of the associated weight gain (10). In the management guidelines for adults with T2DM, insulin or sulfonylureas are only added to the regimen if other medications (GLP-1 RAs, DPP-IV inhibitors and SGLT2 inhibitors) fail to achieve goal HbA1c as both insulin and sulfonylureas promote weight gain, which can worsen insulin resistance and overall health (10).

With the recent FDA-approval of the daily injectable glucagon-like peptide-1 receptor agonist (GLP-1 RA) liraglutide, there is now another safe and effective option for treatment of T2DM in youth that promotes both weight loss and improves glycemic control. GLP-1 RAs mimic 
endogenous GLP-1 hormone action, thereby stimulating endogenous insulin secretion, decreasing glucagon levels, possibly delaying gastric emptying, and decreasing appetite (11). GLP-1RAs may also improve $\beta$-cell function, as shown in animal models, a property that could be especially relevant to youth, secondary to the more progressive nature of B-cell deterioration as compared to adults with T2DM (12-14). Although there are multiple forms of GLP-1 RAs on the market for adults, liraglutide is the only medication of this class approved for youth down to age 10 years. Phase 3 trials of other GLP-1 RAs as well as other classes of medication commonly used in adults (SGLT2 inhibitors and DPP-4 inhibitors) in youth with T2DM are currently ongoing so additional options may be available in the next few years (15).

The Evaluation of Liraglutide in Pediatrics With Diabetes (Ellipse) trial generated the data from which the decision for FDA-approval of liraglutide for youth down to age 10 years was based (16). In the trial, liraglutide doses up to $1.8 \mathrm{mg}$ daily were found to decrease the mean $\mathrm{HbA1c}$ levels by 1.3 percentage points over approximately 1 year and improve fasting glucose in youth (aged 10 to 17 years) with T2DM and overweight/obesity compared to placebo (16). The Ellipse trial did not find a significant reduction in body weight between the liraglutide and placebo groups; mean body weight decreased in both groups at week $26(-2.3 \mathrm{~kg}$ with liraglutide and $-0.99 \mathrm{~kg}$ with placebo) (16). Similarly, a smaller $(n=28)$ randomized, double-blind, placebo-controlled trial found that liraglutide decreased HbAlc over 5 weeks compared to placebo, but did not result in a significant weight loss over this relatively short treatment period (17). Although no GLP-1 RA trials have been conducted in youth with T2DM with a primary focus on weight reduction, GLP1 RAs have been found to promote weight loss in youth with obesity without diabetes (18-20). For example, a randomized, double-blind, placebo-controlled trial evaluating the safety and tolerability of liraglutide in pediatric participants (age 7-11 years) reported that doses up to $3.0 \mathrm{mg}$ daily significantly reduced BMI $\mathrm{z}$-score by $-0.3 \mathrm{~kg} / \mathrm{m}^{2}$ compared to the placebo group (20). In adults, GLP-1 RAs were associated with weight loss in patients with overweight or obesity with and without type 2 diabetes, as well as reduction in adverse cardiovascular outcomes and reduced progression of diabetes-related nephropathy (21-26).

Liraglutide was found to be both safe and well-tolerated in youth with obesity and T2DM with escalating daily doses, up

\section{REFERENCES}

1. Hamman RF, Bell RA, Dabelea D, D'Agostino RB, Dolan L, Imperatore G, et al. The SEARCH for diabetes in youth study: rationale, findings, and future directions. Diabetes Care. (2014) 37:3336-44. doi: 10.2337/dc14-0574

2. Narasimhan S, Weinstock RS. Youth-onset type 2 diabetes: lessons learned from the TODAY study. Mayo Clin Proc. (2014) 89:80616. doi: 10.1016/j.mayocp.2014.01.009

3. Today Study Group. A clinical trial to maintain glycemic control in youth with type 2 diabetes. N Engl J Med. (2012) 366:224756. doi: 10.1056/NEJMoa1109333

4. Springer SC, Silverstein J, Copeland K, Moore KR, Prazar GE, Raymer T, et al. Management of type 2 diabetes mellitus in children and adolescents. Pediatrics. (2013) 131:e648-64. doi: 10.1542/peds.2012-3496 to $1.8 \mathrm{mg}$ daily (T2DM treatment dose) $(16,17,27)$, or $3.0 \mathrm{mg}$ daily (obesity treatment dose) $(20,28)$. In all studies evaluating liraglutide in youth, transient GI side effects (nausea, vomiting, diarrhea, and abdominal pain), similar to those experienced with metformin, were the most commonly reported though these effects can be mitigated with slow up-titration $(16,17,20,28,29)$. Hypoglycemia can also occur with GLP-1 RAs; however, this risk is lower than with insulin and other anti-diabetic medication $(25,30,31)$. No severe hypoglycemia events, defined as plasma glucose $<56 \mathrm{mg} / \mathrm{dL}$, were reported in the five trials of liraglutide in youth $(16,17,20,28)$. In the randomized, double-blind, placebo-controlled trial evaluating the safety and tolerability of liraglutide in pediatric participants without diabetes, mild asymptomatic hypoglycemia, ranging from 62 to $70 \mathrm{mg} / \mathrm{dL}$, was reported in $25 \%$ of participants in the liraglutide-treated group (20). While pancreatitis has been associated with GLP-1 RA use in some adult studies, a meta-analysis of clinical trials did not demonstrate a link between GLP-1 RA treatment and pancreatitis in adults with T2DM $(32,33)$. Incidence of pancreatitis was not reported in the pediatrics trials of liraglutide $(16,17,20,28)$. In general, safety and tolerability profiles in the pediatric trials were comparable to adult studies; and consistent with adult studies, body weight and gender appear to influence liraglutide pharmokinetics $(16,17,20,27,28)$.

Based on results of the SEARCH and TODAY studies published nearly 5 years ago, clinicians treating youth with T2DM have known that treatment with metformin alone will likely be insufficient to decrease diabetes progression and reduce insulin requirements. Furthermore, it is now well-established that adding insulin therapy in an effort to decrease hyperglycemia and prevent retinopathy, neuropathy, and nephropathy will likely exacerbate weight gain and may discourage youth from actively engaging in lifestyle management. The recent FDAapproval of liraglutide presents a safe option to pediatric endocrinologists to avoid weight gain while effectively managing glycemic control. Now is the time to consider GLP-1 RAs as a preferred treatment for youth with T2DM, along with metformin and lifestyle modification.

\section{AUTHOR CONTRIBUTIONS}

All authors listed have made a substantial, direct and intellectual contribution to the work, and approved it for publication.

5. Zeitler P, Fu J, Tandon N, Nadeau K, Urakami T, Barrett $\mathrm{T}$, et al. ISPAD Clinical Practice Consensus Guidelines 2014. Type 2 diabetes in the child and adolescent. Pediatr Diabetes. (2014) 20(Suppl. 1):2646. doi: $10.1111 /$ pedi.12179

6. Arslanian S, Bacha F, Grey M, Marcus MD, White NH, Zeitler P. Evaluation and management of youth-onset type 2 diabetes: a position statement by the American Diabetes Association. Diabetes Care. (2018) 41:264868. doi: $10.2337 /$ dci18-0052

7. Copeland KC, Silverstein J, Moore KR, Prazar GE, Raymer T, Shiffman RN, et al. Management of newly diagnosed type 2 Diabetes Mellitus (T2DM) in children and adolescents. Pediatrics. (2013) 131:364-82. doi: 10.1542/peds.2012-3494

8. Administration UDOFaD. FDA Approves New Treatment for Pediatric Patients with Type 2 Diabetes. (2018). Available online at: https://www. 
fda.gov/news-events/press-announcements/fda-approves-new-treatmentpediatric-patients-type-2-diabetes?utm_campaign=FDA\%20approves $\% 20$ new $\% 20$ treatment $\% 20$ for\%20pediatric\%20patients\&utm_medium = email\&utm_source=Eloqua (accessed August 1, 2019).

9. Russell-Jones D, Khan R. Insulin-associated weight gain in diabetescauses, effects and coping strategies. Diabetes Obes Metab. (2007) 9:799812. doi: 10.1111/j.1463-1326.2006.00686.x

10. Davies MJ, D'Alessio DA, Fradkin J, Kernan WN, Mathieu C, Mingrone G, et al. Management of hyperglycemia in type 2 diabetes, 2018. A consensus report by the American Diabetes Association (ADA) and the European Association for the Study of Diabetes (EASD). Diabetes Care. (2018) 41:2669701. doi: $10.2337 /$ dci18-0033

11. Mcbrayer DN, Tal-Gan Y. Recent advances in GLP-1 receptor agonists for use in diabetes mellitus. Drug Dev Res. (2017) 8:292-9. doi: 10.1002/ddr.21404

12. Hou S, Li C, Huan Y, Liu S, Liu Q, Sun S, et al. Effects of E2HSA, a longacting glucagon like peptide-1 receptor agonist, on glycemic control and beta cell function in spontaneous diabetic $\mathrm{db} / \mathrm{db}$ mice. J Diabetes Res. (2015) 2015:817839. doi: $10.1155 / 2015 / 817839$

13. Liu Z, Habener JF. Glucagon-like peptide-1 activation of TCF7L2-dependent Wnt signaling enhances pancreatic beta cell proliferation. J Biol Chem. (2008) 283:8723-35. doi: 10.1074/jbc.M706105200

14. Guettier JM, Gautam D, Scarselli M, Ruiz de Azua I, Li JH, Rosemond E, et al. A chemical-genetic approach to study G protein regulation of beta cell function in vivo. Proc Natl Acad Sci USA. (2009) 106:19197202. doi: 10.1073 /pnas. 0906593106

15. Tamborlane WV, Haymond MW, Dunger D, Shankar R, Gubitosi-Klug $\mathrm{R}$, Bethin $\mathrm{K}$, et al. Expanding treatment options for youth with type 2 diabetes: current problems and proposed solutions: a white paper from the NICHD Diabetes Working Group. Diabetes Care. (2016) 39:3239. doi: $10.2337 / \mathrm{dc} 15-1649$

16. Tamborlane WV, Barrientos-Pérez M, Fainberg U, Frimer-Larsen H, Hafez M, Hale PM, et al. Liraglutide in children and adolescents with type 2 diabetes. $N$ Engl J Med. (2019) 381:637-46. doi: 10.1056/NEJMoa1903822

17. Klein DJ, Battelino T, Chatterjee DJ, Jacobsen LV, Hale PM, Arslanian S, et al. Liraglutide's safety, tolerability, pharmacokinetics, and pharmacodynamics in pediatric type 2 diabetes: a randomized, double-blind, placebo-controlled trial. Diabetes Technol Ther. (2014) 16:679-87. doi: 10.1089/dia.2013.0366

18. Kelly AS, Metzig AM, Rudser KD, Fitch AK, Fox CK, Nathan BM, et al. Exenatide as a weight-loss therapy in extreme pediatric obesity: a randomized, controlled pilot study. Obesity. (2012) 20:364-70. doi: 10.1038/oby.2011.337

19. Kelly AS, Rudser KD, Nathan BM, Fox CK, Metzig AM, Coombes BJ, et al. The effect of glucagon-like peptide-1 receptor agonist therapy on body mass index in adolescents with severe obesity: a randomized, placebo-controlled, clinical trial. JAMA Peds. (2013) 167:355-60. doi: 10.1001/jamapediatrics.2013.1045

20. Mastrandrea LD, Witten L, Carlsson Petri KC, Hale PM, Hedman HK, Riesenberg RA. Liraglutide effects in a paediatric (7-11 y) population with obesity: a randomized, double-blind, placebo-controlled, short-term trial to assess safety, tolerability, pharmacokinetics, and pharmacodynamics. Pediatr Obes. (2019) 14:12495. doi: 10.1111/ijpo.12495

21. Potts JE, Gray LJ, Brady EM, Khunti K, Davies MJ, Bodicoat DH. The effect of glucagon-like peptide 1 receptor agonists on weight loss in type 2 diabetes: a systematic review and mixed treatment comparison meta-analysis. PLoS ONE. (2015) 10:e0126769. doi: 10.1371/journal.pone.0126769

22. Isaacs D, Prasad-Reddy L, Srivastava SB. Role of glucagon-like peptide 1 receptor agonists in management of obesity. Am J Health Syst Pharm. (2016) 73:1493-507. doi: 10.2146/ajhp150990
23. Bethel MA, Patel RA, Merrill P, Lokhnygina Y, Buse JB, Mentz RJ, et al. Cardiovascular outcomes with glucagon-like peptide-1 receptor agonists in patients with type 2 diabetes: a meta-analysis. Lancet Diabetes Endocrinol, (2018) 6:105-13. doi: 10.1016/S2213-8587(17)30412-6

24. Dicembrini I, Nreu B, Scatena A, Andreozzi F, Sesti G, Mannucci E, et al. Microvascular effects of glucagon-like peptide-1 receptor agonists in type 2 diabetes: a meta-analysis of randomized controlled trials. Acta Diabetol. (2017) 54:933-41. doi: 10.1007/s00592-017-1031-9

25. Abd El Aziz MS, Kahle M, Meier J, Nauck MA. A meta-analysis comparing clinical effects of short- or long-acting GLP-1 receptor agonists versus insulin treatment from head-to-head studies in type 2 diabetic patients. Diabetes Obes Metab. (2017) 19:216-27. doi: 10.1111/dom.12804

26. Jendle J, Nauck MA, Matthews DR, Frid A, Hermansen K, Düring M, et al. Weight loss with liraglutide, a once-daily human glucagon-like peptide1 analogue for type 2 diabetes treatment as monotherapy or added to metformin, is primarily as a result of a reduction in fat tissue. Diabetes Obes Metab. (2009) 11:1163-72. doi: 10.1111/j.1463-1326.2009.01158.x

27. Petri KC, Jacobsen LV, Klein DJ. Comparable liraglutide pharmacokinetics in pediatric and adult populations with type 2 diabetes: a population pharmacokinetic analysis. Clin Pharmacokinet. (2015) 54:663-70. doi: 10.1007/s40262-014-0229-z

28. Danne T, Biester T, Kapitzke K, Jacobsen SH, Jacobsen LV, Petri KCC, et al. Liraglutide in an adolescent population with obesity: a randomized, double-blind, placebo-controlled 5-week trial to assess safety, tolerability, and pharmacokinetics of liraglutide in adolescents aged 12-17 years. J Pediatr. (2017) 181:146-53.e3. doi: 10.1016/j.jpeds.2016.10.076

29. Filippatos TD, Panagiotopoulou TV, Elisaf MS. Adverse effects of GLP-1 receptor agonists. Rev Diabet Stud. (2014) 11:20230. doi: 10.1900/RDS.2014.11.202

30. Nauck M, Frid A, Hermansen K, Shah NS, Tankova T, Mitha IH, et al. Efficacy and safety comparison of liraglutide, glimepiride, and placebo, all in combination with metformin, in type 2 diabetes: the LEAD (liraglutide effect and action in diabetes)-2 study. Diabetes Care. (2009) 32:8490. doi: $10.2337 / \mathrm{dc} 08-1355$

31. Amori RE, Lau J, Pittas AG. Efficacy and safety of incretin therapy in type 2 diabetes: systematic review and meta-analysis. JAMA. (2007) 298:194206. doi: 10.1001/jama.298.2.194

32. Storgaard H, Cold F, Gluud LL, Vilsbøll T, Knop FK. Glucagon-like peptide-1 receptor agonists and risk of acute pancreatitis in patients with type 2 diabetes. Diabetes Obes Metab. (2017) 19:906-8. doi: 10.1111/dom.12885

33. Monami M, Dicembrini I, Nardini C, Fiordelli I, Mannucci E. Glucagonlike peptide-1 receptor agonists and pancreatitis: a meta-analysis of randomized clinical trials. Diabetes Res Clin Pract. (2014) 103:26975. doi: 10.1016/j.diabres.2014.01.010

Conflict of Interest: MO serves as site PI for study through Vivus Pharmaceuticals. AK receives research support (drug/placebo) from Astra Zeneca Pharmaceuticals and serves as a consultant for Novo Nordisk, Orexigen, and Vivus Pharmaceuticals but does not accept personal or professional income for these activities.

Copyright (C) 2019 Oberle and Kelly. This is an open-access article distributed under the terms of the Creative Commons Attribution License (CC BY). The use, distribution or reproduction in other forums is permitted, provided the original author(s) and the copyright owner(s) are credited and that the original publication in this journal is cited, in accordance with accepted academic practice. No use, distribution or reproduction is permitted which does not comply with these terms. 